\title{
Effect of Lactobacillus Species Probiotics on Growth Performance of Dual-Purpose Chicken
}

This article was published in the following Dove Press journal:

Veterinary Medicine: Research and Reports

\author{
Haben Fesseha $\mathbb{D}^{1}$ \\ Tigabu Demlie ${ }^{2}$ \\ Mesfin Mathewos $\mathbb{1}^{3}$ \\ Eyob Eshetu ${ }^{4}$
}

'Department of Veterinary Surgery and Diagnostic Imaging, Wolaita Sodo University, School of Veterinary Medicine, Wolaita Sodo, Ethiopia; ${ }^{2}$ Department of Veterinary Clinical Laboratory Science, School of Veterinary Medicine, Wollo University, Dessie, Ethiopia; ${ }^{3}$ Department of Veterinary Pathology, Wolaita Sodo University, School of Veterinary Medicine, Wolaita Sodo, Ethiopia; ${ }^{4}$ Department of Veterinary Parasitology, Wolaita Sodo University, School of Veterinary

Medicine, Wolaita Sodo, Ethiopia
Correspondence: Haben Fesseha Email haben.senbetu@wsu.edu.et
Introduction: In-feed probiotics are becoming attractive alternatives to antibiotics in the poultry industry due to the ever-growing strict prohibitions on antibiotic growth promoters (AGP) in animal production.

Methods: The study was conducted to investigate the effects of Lactobacillus paracaseis sparacasei and Lactobacillus rhamnosus on the growth performance of 120 day-olds randomly selected Sasso dual-purpose chicken. They were divided into four groups with two replicates per group and 15 chicks per replicate. The treatments were $\mathrm{T}_{1}$ (control), $\mathrm{T}_{2}$ (supplement diet with $4 \mathrm{~g}$ probiotic), $\mathrm{T}_{3}$ (supplement diet with $2 \mathrm{~g}$ probiotic), $\mathrm{T}_{4}$ (supplement diet with $1 \mathrm{~g}$ probiotic). The experimental feeding trials were conducted after two weeks adaptation period.

Results: The present findings revealed that the chickens supplemented with Lactobacillus species probiotics during the first week of age have shown higher body weight than control $(p<0.05)$. The feed intake of week one of $\mathrm{T}_{2}$ and $\mathrm{T}_{3}$ were significantly higher $(p<0.05)$ than the $\mathrm{T}_{1}$ (control). However, there was no significant difference $(p>0.05)$ in feed intake in the $2^{\text {nd }}, 3^{\text {rd }}, 4^{\text {th }}$, and $5^{\text {th }}$ weeks of all treatment groups. The present result showed that there was a significant body weight gain $(p<0.05)$ in all probiotic fed groups than the control group. The highest body weight gain was observed in chickens found in the T4 treatment group. Whereas the body weight gains significantly higher and improved the feed conversion $(p<0.05)$ in the $T_{2}$ and $T_{4}$ than the $T_{1}$ (control). However, the feed conversion ratio was significantly influenced by probiotic inclusion in $\mathrm{T}_{3}$ as compared to the control group.

Conclusion: Overall, the results suggest that Lactobacillus paracaseis sparacasei and Lactobacillus rhamnosus have a positive effect on the growth performance of broilers.

Keywords: Body weight gain, Broiler, Chicken, Lactobacillus species, Probiotics

\section{Introduction}

Ethiopia possesses an estimated number of 60.51 million poultry. Poultry production has great importance as a primary supplier of eggs and meat, sources of cash income. The sub-sector remains one of the most common and economically rewarding means of providing animal proteins that contribute significantly to the protection of food and nutrition. ${ }^{1}$

The demand for chicken meat is evolving. Consumers are now becoming more conscious and more aware of items viewed as "naturally or organic" products., Commercial poultry production is a leading source of animal protein, and the poultry industry has grown in scale faster than other livestock producers, ${ }^{4,5}$ however, there is a major challenge on sustainable availability of high-quality feed at a minimum cost. A feed is a significant component of the overall production cost of 
poultry. Enteric conditions in the poultry industry are also one of the main issues. These diseases are responsible for lower rates of growth and consequent economic gains due to a lower weight gain, higher death rates, lower feed conversion rates (FCR), and higher prescription prices. ${ }^{6,7}$ Antibiotic supplementation as sub-therapeutics improves the efficiency of chicken feed and preserves gut health, growth, and development. ${ }^{8}$

Birds provide a comparatively robust and durable intestinal microbial composition across time. It is necessary to avoid pathogenic infections, to allow complex plant fibers to be digested into short chains of fatty acids, to synthesize essential vitamins and amino acids, to control fat metabolism, and to form the production of the immune system. ${ }^{9-11}$ The Intestinal microbial population is a healthy dietary alterations and plays important roles in the physiology and health of the host. ${ }^{12-14}$ However, various environmental factors such as feed, stress, viruses, and medicines, especially antibiotics, may trigger intestinal dysbacteriosis and dysregulation of the immunity in birds. Hence, bird health and bird development may be impacted and intestinal necrotic diseases may occur. ${ }^{15-18}$

In the poultry industry, antibiotics have been first used as a feed additive in the 1940s and were commonly used to stimulate development over the last few decades. In-feed antibiotic growth promoters (AGP) have proved to be successful in improving food-animal health and production by avoiding gastrointestinal infection, reducing morbidity and mortality, and maximizing the quality of feed usage. ${ }^{19-21}$ Also, the widespread use of antibiotics in poultry products may produce antibiotic-resistant bacteria. ${ }^{22}$ The use of antibiotics as a promoter of poultry growth in animal diets has been restricted in many countries. ${ }^{23}$

With the strict prohibition of antibiotics, the search for healthy substitutes for antibiotics in the processing of food animals is becoming exceedingly important. During the past several decades, the efficiency and overall health of food animals are improved by many types of dietary substitutes, such as directly feed microbials such as probiotics, prebiotics, and natural minerals; these dietary alternatives were seen as "Generally Recognized as Safe (GRAS)" alternatives to antibiotics. $^{24-26}$

Probiotics are defined as a culture of live microorganisms that are beneficial to the host by improving the properties of the indigenous microbiota when applied to animals. $^{22}$

Non-pathogenic, non-toxic, and able to exert a beneficial effect on the host animal should be the characterstics of a healthy probiotic. They should be present in the gut environment as viable cells and capable of survival and metabolization. Also under storage and field conditions, it should be stable and able to remain viable for longer periods. By promoting the development of beneficial microorganisms, the value of probiotic consumption reduces the risk of gastrointestinal diseases. Probiotic supplementation enhances the bioavailability of nutrients, and avoidance or elimination of allergies in susceptible individuals. $^{27}$

Due to pathogen inhibition, the observed results after probiotic supplementation are linked to a more favorable microbial community in the gut. Pathogen inhibition mechanisms may involve immune system activation, competition for available nutrients, and direct antimicrobial effects through secretion of inhibitory substances or competition for intestinal epithelium adhesion receptors. ${ }^{28,29}$

Lactobacilli species are microaerophilic gram-positive bacteria typically contained in milk, fruits, and soil. They retain the natural equilibrium in chicken intestines while preserving the natural stability of the microflora. ${ }^{30,31}$ They decrease the fat content in the body and serum and increase the efficiency of poultry. It may also be used as an alternative for antibiotics in the form of supplements. There are many reasons to concentrate on the use of Lactobacilli species: (1) Lactobacilli showed "competitive exclusion", (2) Lactobacilli bind quickly to the gut epithelial cells and (3) Lactobacilli affect the immune system and understand that they are healthy symbionts for the host. ${ }^{32}$

Several previous reports had shown that commercial probiotics that contain at least $1 \times 10^{8} \mathrm{CFU} \mathrm{g}^{-1}$ Lactobacillus casei, Lactobacillus acidophilus, Bifidobacterium thermophilum, and Enterococcus faecium improves the growth performance, feed efficiency, the immune response of broiler chickens and act as a replacement for antibiotic growth promoters. ${ }^{33-38}$ The ability of probiotics can be increased by choosing potent strains, gene manipulation, combining two or more strains, combining probiotics, and synergistic components that affect the host. ${ }^{4}$

As attractive replacements to AGP, numerous studies have reported that probiotics are beneficial for the growth performance and animal health through enhancing the intestinal development and nutrients absorption, regulating the mucosal immune system, inhibiting intestinal pathogen colonization and infection, and reshaping intestinal microbiota. ${ }^{24,39}$ Lack of evidence as to their mechanism of action and the impact on host animals is the issue with probiotics. In some cases, probiotics are effective 
particularly in newborn animals or those that have been treated with antibiotics, where they have the same effect as products of competitive exclusion. They can also be effective in improving weight gain and feeding conversion rates. ${ }^{40}$ The search for new, effective, and non-toxic feed additives on poultry growth against unexpected hazards is still continuing. From this point of view, the research was conducted to study the effects of probiotic supplementation in broiler chickens on growth efficiency.

\section{Materials and Methods Experimental Animals}

Day-old broilers Sasso breed were purchased and selected for the current study from EthioChicken. The deep litter experimental house was prepared, cleaned, and disinfected before the introduction of experimental chickens. Chicks were vaccinated against Infectious bursal disease, Marek's disease, and Newcastle disease. Feed was measured and offered twice a day and fresh and clean water were also provided daily. Daily feed refusals in each replicate were collected, weighed, and recorded before the daily feed offer.

\section{Feed Supplements}

A commercial diet was used in the study. The nutritional composition of diets fed during the starter (1-21 days of age), grower (22-42 days of age), and finisher (42-56 days of age) periods (Table 1).

\section{Experimental Design and Dietary Treatment}

A total of 120 chickens were used during this experimental study. Fifteen chickens were randomly assigned to each of

Table I Common Ingredients of Commercial Diet

\begin{tabular}{|l|l|l|l|}
\hline Ingredients & $\begin{array}{l}\text { Broiler } \\
\text { Starter } \\
\text { (I-2I Days) }\end{array}$ & $\begin{array}{l}\text { Broiler } \\
\text { Grower } \\
\mathbf{( 2 2 - 4 2} \text { Days) }\end{array}$ & $\begin{array}{l}\text { Broiler } \\
\text { Finisher } \\
\mathbf{( 4 3 - 5 6} \text { Days) }\end{array}$ \\
\hline Protein & $20.9 \%$ & $19.7 \%$ & $18 \%$ \\
\hline Fat & $3 \%$ & $2.50 \%$ & $8 \%$ \\
\hline Fiber & $4.5 \%$ & $5 \%$ & $5.5 \%$ \\
\hline Calcium & $1.15 \%$ & $1.10 \%$ & $0.65 \%$ \\
\hline $\begin{array}{l}\text { Energy (kcal/ } \\
\text { kg) }\end{array}$ & 3035 & 2958 & 3250 \\
\hline Moisture & $10 \%$ & $10 \%$ & $10 \%$ \\
\hline
\end{tabular}

two replicates of the four treatment groups to adapt the experimental diet and procedure before the actual research started. The experiment was conducted in a completely randomized design with four dietary treatments each with two replications. A total of 120 chickens were randomly distributed to 8 pens having four groups with two replicates per each group and 15 chicks per replicate and two of the pens were received the same diet which was allocated to the pen.

\section{Probiotics Preparation and Sample Collection}

Lactobacillus paracasei is a rod-shaped (bacillus shape) bacterium with a width of 2.0 to $4.0 \mu \mathrm{m}$ and a length of 0.8 to $1.0 \mu \mathrm{m}$. It is commonly found in many human and animal habitats such as human intestinal tracts and mouths as well as sewages, silages, and dairy products. It helps to strengthen the immune function, oxidative stress, body fat reduction. ${ }^{41,42}$ Lactobacillus rhamnosus is a kind of friendly bacteria found in the intestines. Its health advantages include relief of Irritable bowel syndrome (IBS) symptoms, the treatment of diarrhea, enhancement of gut health, and cavity defense. L. rhamnosus is present in some milk products as a probiotic supplement. ${ }^{43}$ Some strains of $L$. rhamnosus bacteria are particularly useful in treating infections of the female urogenital tract and endocarditis. ${ }^{44,45}$

The strains Lactobacillus paracaseis sparacasei and Lactobacillus rhamnosus were isolated from the gut region of the chick and confirmed at species level using the Biolog ${ }^{\mathrm{TM}}$ Identification system and passed the necessary in vitro probiotic screening test were obtained from Microbiology laboratory, School of Veterinary Medicine. A co-culture of Lactobacillus strains (equal volume of 0.5 McFarland turbidity standards) was propagated on sterile de Man, Rogosa, and Sharpe (MRS) broth and harvested to prepared experimental feed. The probiotic-containing feed was prepared as treatment groups were $T_{1}$ (control), $T_{2}$ (supplement diet with $4 \mathrm{~g}$ probiotic $/ \mathrm{kg}$ feed), $\mathrm{T}_{3}$ (supplement diet with $2 \mathrm{~g}$ probiotic $/ \mathrm{kg}$ ), $\mathrm{T}_{4}$ (supplement diet with $1 \mathrm{~g}$ probiotic $/ \mathrm{kg}$ ). The chickens were provided with the experimental feed every three days for five consecutive weeks.

On day $1^{\text {st }}, 2^{\text {nd }}, 3^{\text {rd }}, 4^{\text {th }}$, and $5^{\text {th }}$ weeks of age, three birds from each replicate were chosen randomly and weighed after deprivation of feed overnight.

\section{Data Management and Statistical Analysis}

The data collected during the study period were subjected to statistical analysis using STATA version 13. Descriptive 
Table 2 Effects Probiotic Supplementation on Broiler Body Weight

\begin{tabular}{|l|l|l|l|l|l|}
\hline \multirow{2}{*}{ Week } & \multicolumn{5}{|c|}{ Treatment Groups } \\
\cline { 2 - 6 } & $\mathbf{T}_{\mathbf{1}}$ & $\mathbf{T}_{\mathbf{2}}$ & $\mathbf{T}_{\mathbf{3}}$ & $\mathbf{T}_{\mathbf{4}}$ & P-value \\
\hline Initial & $129.8 \pm 5.87$ & $133.07 \pm 0.71$ & $125.31 \pm 4.70$ & $134.50 \pm 7.35$ & 0.417 \\
$I^{\text {st }}$ & $459.85 \pm 14^{*}$ & $482.09 \pm 11.12^{*}$ & $455.47 \pm 14.67$ & $470.41 \pm 6.46$ & 0.000 \\
$2^{\text {nd }}$ & $691.67 \pm 12^{*}$ & $740.02 \pm 9.45^{*}$ & $692.665 \pm 10.37$ & $738.33 \pm 7.07^{*}$ & 0.011 \\
$3^{\text {rd }}$ & $925.89 \pm 2.5^{*}$ & $959.28 \pm 49.2^{*}$ & $907.09 \pm 14.87$ & $933.94 \pm 11.59$ & 0.000 \\
$4^{\text {th }}$ & $1173.35 \pm 3.7$ & $1210.65 \pm 5.45$ & $1112.05 \pm 13.93$ & $1216.55 \pm 59.89$ & 0.1184 \\
$5^{\text {th }}$ & $1435.87 \pm 27^{*}$ & $1557.10 \pm 104.0^{*}$ & $1397.05 \pm 20.22$ & $1556.17 \pm 133.4^{*}$ & 0.0000 \\
\hline
\end{tabular}

Note: Means bearing *Superscript were significant values of the Post-hoc Honest Significant Difference $(H S D)$ test $(P<0.05)$.

statistics were employed to summarize the data and expressed in terms of mean and standard deviation. Oneway ANOVA and the post hoc Tukey's test were performed to identify significant differences between the four feeding treatments. Levels of significant differences were detected at 95\% confidence interval and $P<0.05$.

\section{Results}

In this study to evaluate the effect of probiotics on the growth performance of broiler chickens on body weight, body weight gain, feed intake, and feed conversion ratio were recorded. Bodyweight at the beginning of the experiment was not a significant difference among groups $(P>0.05)$. Bodyweight of the broilers' week wise showed that at the first week of treatment the bodyweight of broilers with Probiotic supplemented diet results numerically higher body weight than without probiotic $(P<0.05)$ despite the Bodyweight of $\mathrm{T}_{2}$ and $\mathrm{T}_{4}$ treatment groups were found significantly different from $\mathrm{T}_{1}$ and $\mathrm{T}_{3}$ treatment groups $(p<0.05)$. In the $2^{\text {nd }}$ week, there was a significant difference between $\mathrm{T}_{1}$ (control) and other treatment groups $\mathrm{T}_{2}, \mathrm{~T}_{3}$, and $\mathrm{T}_{4}$. Even though $\mathrm{T}_{2}$ and $\mathrm{T}_{4}$ showed slightly higher body weight than $\mathrm{T}_{1}$ and $T_{3}$ treatment groups. Whereas in the $4^{\text {th }}$ week $T_{2}$ and $\mathrm{T}_{4}$ showed slightly higher body weight than $T_{1}$ and $T_{3}$ treatment groups and in the $5^{\text {th }}$ week $\mathrm{T}_{3}$ slightly lower than treatment groups (Table- 2).

The feed intake of week one of $\mathrm{T}_{2}$ and $\mathrm{T}_{3}$ were significantly higher $(p<0.05)$ than the $T_{1}$ (control). However, there was no significant difference $(p>0.05)$ in feed intake in the $2^{\text {nd }}, 3^{\text {rd }}, 4^{\text {th }}$, and $5^{\text {th }}$ week of the treatment groups (Table 3).

The present result showed that there was a significant difference $(p<0.05)$ between the control and probiotic fed group in the first and second week on body weight gain and in the $3^{\text {rd }}$ week $T_{1}$ (control) higher value than probiotic supplementation treatment groups. While in the fourth week, $\mathrm{T}_{4}$ was higher body weight gain than the control and other treatment groups. In the fifth week, there was a significant difference $(P<0.05)$ among different treatments, and the highest body weight gain was observed $\mathrm{T}_{4}$ with probiotic supplementation treatment groups. Whereas the final body weight gains significantly higher $(p<0.05)$ in the $T_{2}$ and $T_{4}$ than the $T_{1}$ (control) (Table 4).

The current study shows that the data on total feed intake, total body weight gain (BWG), and FCR in broilers were influenced by probiotic feed treatments. The results indicated that there was a significant $(P<0.05)$ difference in feed intake in the treatment groups than in the control. The $\mathrm{T}_{2}$ and $\mathrm{T}_{4}$ treatment groups were significantly improved final body weight during the experimental period. The feed

Table 3 Effects Probiotic Supplementation on Broiler Feed Intake

\begin{tabular}{|l|l|l|l|l|l|}
\hline \multirow{2}{*}{ Week } & \multicolumn{5}{|c|}{ Treatment Groups } \\
\cline { 2 - 6 } & $\mathbf{T}_{\mathbf{1}}$ & $\mathbf{T}_{\mathbf{2}}$ & $\mathbf{T}_{\mathbf{3}}$ & $\mathbf{T}_{\mathbf{4}}$ & $\mathbf{P}$-value \\
\hline $1^{\text {st }}$ & $688.63 \pm 62.84$ & $802.89 \pm 40.55$ & $828.93 \pm 58.9$ & $799.98 \pm 28.78$ & 0.000 \\
$2^{\text {nd }}$ & $955.95 \pm 59.47$ & $943.69 \pm 51.79$ & $961.07 \pm 42.23$ & $979.1 \pm 93.82$ & 0.782 \\
$3^{\text {rd }}$ & $1072.96 \pm 93.7$ & $1132.09 \pm 83.2$ & $1190.57 \pm 86.53$ & $1185.1 \pm 53.98$ & 0.0502 \\
$4^{\text {th }}$ & $1414.06 \pm 144.06$ & $1426.2 \pm 123.02$ & $1411.3 \pm 85.94$ & $1448.65 \pm 130.1$ & 0.939 \\
$5^{\text {th }}$ & $1711.7 \pm 60$ & $1725.6 \pm 53.69$ & $1727.1 \pm 57.08$ & $1730.04 \pm 52.3$ & 0.929 \\
\hline
\end{tabular}


Table 4 Effects Probiotic Supplementation on Broiler Body Weight Gain

\begin{tabular}{|c|c|c|c|c|c|}
\hline \multirow[t]{2}{*}{ Week } & \multicolumn{5}{|c|}{ Treatment Groups } \\
\hline & $\mathbf{T}_{\mathbf{1}}$ & $\mathbf{T}_{\mathbf{2}}$ & $T_{3}$ & $\mathbf{T}_{4}$ & P-value \\
\hline $1^{\text {st }}$ & $330.05 \pm 11.98 *$ & $349.02 \pm 11.82 *$ & $330.17 \pm 19.37$ & $335.91 \pm 13.82$ & 0.002 \\
\hline $2^{\text {nd }}$ & $231.81 \pm 15.68^{*}$ & $257.93 \pm 8.34^{*}$ & $237.20 \pm 4.29$ & $267.92 \pm 10.6 I^{*}$ & 0.000 \\
\hline $3^{\text {rd }}$ & $234.22 \pm 9.43^{*}$ & $219.26 \pm 58.87$ & $214.42 \pm 4.50$ & $195.6 \pm 4.52 *$ & 0.026 \\
\hline $4^{\text {th }}$ & $247.465 \pm 11.37^{*}$ & $251.37 \pm 24$ & $204.96 \pm 10.94 *$ & $282.61 \pm 18.30$ & 0.000 \\
\hline $5^{\text {th }}$ & $262.52 \pm 12.04^{*}$ & $276.44 \pm 29.26$ & $284.96 \pm 6.29$ & $339.62 \pm 10.84 *$ & 0.000 \\
\hline Final BWG & $1306.07 \pm 27.56 *$ & $\left.|424.03 \pm| 05.4\right|^{*}$ & $127 \mid .70 \pm 24.92$ & $|42| .67 \pm|4| .09 *$ & 0.000 \\
\hline
\end{tabular}

Note: Means bearing *superscript were significant values, values of Post-hoc HSD test $(p<0.05)$.

conversion ratio was significantly $(P<0.05)$ improved in $\mathrm{T}_{2}$ and $\mathrm{T}_{4}$ than $\mathrm{T}_{1}$ (control). However, the feed conversion ratio was significantly influenced by probiotic inclusion in $T_{3}$ compared to the control group (Table 5).

\section{Discussion}

Probiotics have been considered as an attractive alternative to in-feed antibiotics for their unique functions, including preventing intestinal infectious diseases, enhancing overall health and performance of poultry, and improving the quality of poultry products. ${ }^{24,26,46}$ The present study also revealed that the supplementation of two selected probiotics, Lactobacillus paracaseis sparacasei, and Lactobacillus rhamnosus, are also beneficial in improving the growth performance (BW, weight increments, and FCR) of dual chickens. Similarly, previous studies by Singh et $\mathrm{al}^{47}$ Banday and Risam, ${ }^{48}$ Forte et $\mathrm{al}^{3}$ Park et $\mathrm{al}^{49}$ Ramlucken et $\mathrm{al}^{50-53}$ had also reported that dietary probiotic supplementation may increase broiler growth efficiency by increasing feed conversion and improving gut health. The reason for the growing interest in dietary probiotics is to limit or eradicate the use of feedback antibiotics in the development of food animals.

Initially, a positive effect was expected in light of previous reports showing that dietary probiotics increased growth performance and nutrient utilization in broiler chickens. $^{54-57}$ Mookiah et $\mathrm{al}^{58}$ reported a significant increase in body weight gain and feed efficiency when birds were fed diets supplemented with isomalto- oligosaccharides and 11 strains of Lactobacillus species. Probiotics can protect the integrity of the intestinal structure, deter infections from proliferating, generate digestive enzymes, and improve nutrient consumption, all of which can stimulate animal growth and development. ${ }^{59,60}$

Moreover, the results of the current investigation is in accordance with those obtained in studies by Forte et $\mathrm{al}^{3}$ that used Lactobacillus species on local or rural breed chickens, Salarmoini and Fooladi, ${ }^{61}$ that used Lactobacillus species alone or in combination with other Lactobacillus strains. ${ }^{62-67}$ The findings obtained in this analysis in particular are in line with those obtained by Khan et al ${ }^{68}$ using Lactobacillus strains in Kabir chickens. The findings resulting from dietary supplementation confirm the positive effects found in the production of chickens included in this study.

The present outcomes revealed that there was a statistically significant $(\mathrm{p}<0.05)$ difference between probiotics groups and the control group in Bodyweight gain. Dhande et $\mathrm{al}^{69}$ have reported similar body weight gain was observed in the chicks fed on probiotic supplemented diet than chicks fed on the diet without probiotics. The findings of this research also coincide with the previous findings of Kabir et $\mathrm{al}^{70}$. Bai et $\mathrm{al}^{71}$ and Anjum et $\mathrm{al}^{72}$ who reported that the growth performance of broilers was increased after feeding probiotics. On the other hand reports by Poorghasemi et $\mathrm{al}^{73}$ demonstrated that there was both a significant increase and decrease in body weight gain of the birds after lactofeed probiotic as compared to the control group. Another study by

Table 5 Effects Probiotic Supplementation on Broiler Feed Conversion Ratio

\begin{tabular}{|l|l|l|l|l|l|}
\hline Parameter & $\mathbf{T}_{\mathbf{1}}$ & $\mathbf{T}_{\mathbf{2}}$ & $\mathbf{T}_{\mathbf{3}}$ & $\mathbf{T}_{\mathbf{4}}$ & P-value \\
\hline Total FI & $2726.90 \pm 22.82^{*}$ & $2760.53 \pm 22.90^{*}$ & $2800.311 \pm 21.96^{*}$ & $2813.392 \pm 22.7 *$ & 0.000 \\
Total BWG & $1306.07 \pm 27.56^{*}$ & $1424.03 \pm 105.4 I^{*}$ & $1271.70 \pm 24.92$ & $1421.67 \pm 141.09$ & 0.000 \\
FCR & $2.088 \pm 0.054^{*}$ & $1.94 \pm 0.08^{*}$ & $2.21 \pm 0.046^{*}$ & $1.98 \pm 0.13^{*}$ & 0.000 \\
\hline
\end{tabular}

Note: Means bearing *superscript were significant values, values of Post-hoc HSD test $(p<0.05)$. 
Poorghasemi et $\mathrm{al}^{74}$ also revealed that there was significant variation $(\mathrm{P}<0.05)$ in terms of body weight gains in all treatment groups (except the probiotic group) during the starter period as compared to the control group. While during the grower period, no significant variation was observed between the treatment groups and the controls one.

However, the current finding was in contrast to the previous finding of $\mathrm{Yu}$ et al (2007) that reported, during the growing or finishing periods, the probiotic inclusion did not significantly affect the body weight gain, feed intake, and feed conversion. It is also similar to the finding of Nafees and Pagthinathan ${ }^{75}$ and Biernasiak and Slizewska ${ }^{76}$ who reported that probiotics did not affect the growth improvement of the broilers. Similarly, Samanta, ${ }^{77}$ Awad et al $^{56}$ Roshanfekr and Mamooee, ${ }^{78}$ Ramarao et $\mathrm{al}^{50}$ and Yalcinkayal et $\mathrm{al}^{79}$ reported that probiotic supplementation in broilers ration had no significant effects on body weight gain.

The reason for the discrepancy between the results observed in the aforementioned studies could be related to the duration and time of feeding, diversity of probiotic formulations (mono-species/mono-strain, or mono-species /multistrain, or multispecies, or even multi genera), administration methods (specific dosages in feed and/or in water), general characteristics of probiotic, such as the production of lactic acid, the competitive elimination of pathogenic bacteria, and the improvement of the condition of the intestine, chicken genotypes and rearing systems. ${ }^{80,81}$ Besides, pure broiler chicken fed with probiotics starting from day-old may show a positive response to their growth performance. The differences in the environmental conditions, as well as management (nutritional constituents, humidity, light, ventilation capacity, feeding process, drinking water quality, and other physiological parameters) existing during the experiments, may also contribute to the variation.

In the present study, it was observed that the broilers fed with probiotic supplemented diet throughout the experimental period had consumed significantly more feed as compared to the control group. The findings of Poorghasemi et $\mathrm{al}^{74}$ Kalavathy et $\mathrm{al}^{62}$ and Ramarao et $\mathrm{al}^{50}$ have shown that broilers diet supplemented with probiotics showed improved feed intake compared to the control group. This can be substantiated from the fact that the experimental broilers had consumed significantly more feed than control ones due to increased digestive efficiency. These findings in line with the different research conducted by Onderci et al ${ }^{82}$ Gunal et $\mathrm{al}^{83}$ and Onderci et $\mathrm{al}^{84}$. Moreover, Probiotics improve the digestive process via increase of the useful microbial population, enzymatic activity of bacteria, and the improvement of intestine microbial balance with consequent effects on food digestion, absorption, and intake. ${ }^{85}$

The present findings also indicated a significantly better feed conversion ratio (FCR) on probiotic supplementation in the diet of commercial dual-purpose chickens and unlike the result reported by Mohan et $\mathrm{al}^{86}$ there were no significant differences in the final weight and FCR among the treatment groups with different concentrations of probiotic. This result was also not supported by Ignatova et $\mathrm{al}^{87}$ and Sen et $\mathrm{al}^{88}$ whereas Rahimi et $\mathrm{al}^{89}$ are reported that there was no significant benefit with probiotic addition to the broilers feed. The differences could be due to different factors that could alter the efficacy of a probiotic, such as strains of bacteria utilized, composition and viability of the probiotic bacteria, and the preparation methods.

In general, during comparison of studies regarding probiotics, it is essential to consider that mechanisms of action and beneficial effects are suggested to be specific for genus, species, and strain of the examined microorganisms. ${ }^{90}$ Furthermore, the variation of a probiotic's efficacy could be due to external experimental conditions, other than to the differences in the preparation itself. ${ }^{91}$

\section{Conclusion}

In conclusion, the finding of the current study has shown that the two screened probiotics, Lactobacillus paracaseis sparacasei and Lactobacillus rhamnosus, were beneficial for the growth performance by improving body weight gain, feed conversion ratio, feed intake, and positively affects the growth of the chicken. Furthermore, the adaptability of Lactobacillus paracaseis Sparacasei and Lactobacillus rhamnosus could provide a solution to address the needs of the current generation of ecologically aware consumers. More studies should be done with different rurally reared chickens and a different management system. Further studies characterized by a systematic approach and the use of advanced technologies will be needed to fully comprehend the mechanisms of action of the probiotic strains and to better assess their use in poultry nutrition. 


\section{Ethics Approval and Consent to Participate}

All experimental procedures (animal care, sampling) were conducted following the standards established by the College Research Ethics Committee at the Wolaita Sodo University, Ethiopia. Animal experimentation in the study was approved by the University Research Board.

\section{Disclosure}

All authors declared no conflicts of interest in this work.

\section{References}

1. Central Statistical Agency. Report on livestock and livestock characteristics. The federal democratic republic of ethiopia, private peasant holdings, statistical bulletin 570. Addis Ababa, Ethiopia: CSA; 2017

2. Samant SS, Seo H-S. Effects of label understanding level on consumers' visual attention toward sustainability and process-related label claims found on chicken meat products. Food Qual Prefer. 2016;50:48-56. doi:10.1016/j.foodqual.2016.01.002

3. Forte C, Manuali E, Abbate Y, et al. Dietary Lactobacillus acidophilus positively influences growth performance, gut morphology, and gut microbiology in rurally reared chickens. Poult Sci. 2018;97 (3):930-936. doi:10.3382/ps/pex396

4. Parsa M, Nosrati M, Javandel F, et al. The effects of dietary supplementation with different levels of Microzist as newly developed probiotics on growth performance, carcass characteristics, and immunological organs of broiler chicks. J Appl Animal Res. 2018;46 (1):1097-1102. doi:10.1080/09712119.2018.1467835

5. Royan M. The use of enterococci as probiotics in poultry. Iran J Appl Animal Sci. 2018;8(4):559-565.

6. Ohimain EI, Ofongo RT. The effect of probiotic and prebiotic feed supplementation on chicken health and gut microflora: a review. Int J Animal Vet Adv. 2012;4(2):135-143.

7. Timbermont L, Haesebrouck F, Ducatelle R, et al. Necrotic enteritis in broilers: an updated review on the pathogenesis. Avian Pathol. 2011;40:341-347. doi:10.1080/03079457.2011.590967

8. Danzeisen JL. Modulations of the chicken cecal microbiome and metagenome in response to anticoccidial and growth promoter treatment. PLoS One. 2011;6(11):e27949. doi:10.1371/journal. pone.0027949

9. Blander JM, Longman RS, Iliev ID, et al. Regulation of inflammation by microbiota interactions with the host. Nat Immunol. 2017;18:851-860. doi:10.1038/ni.3780

10. Ahmed I, Roy BC, Khan SA. et al. Microbiome, metabolome, and inflammatory bowel disease. Microorganisms;2016. 4. doi:10.3390/ microorganisms 4020020

11. Clemente JC, Manasson J, Scher JU. The role of the gut microbiome in systemic inflammatory disease. BMJ-Brit Med J. 2018;360.

12. Pan D, Yu Z. Intestinal microbiome of poultry and its interaction with host and diet. Gut Microbes. 2014;5(1):108-119. doi:10.4161/gmic.26945

13. Caballero S, Pamer EG. Microbiota-Mediated Inflammation and Antimicrobial Defense in the Intestine. Annu Rev Immunol. 2015;33:227-256. doi:10.1146/annurev-immunol-032713-120238

14. Hooper LV, Littman DR, Macpherson AJ. Interactions between the microbiota and the immune system. Science. 2012;336:1268-1273. doi: $10.1126 /$ science. 1223490

15. Isaac S, Scher JU, Djukovic A, et al. Short- and long-term effects of oral vancomycin on the human intestinal microbiota. J Antimicrob Chemother. 2017;72:128-136. doi:10.1093/jac/dkw383
16. Kernbauer E, Ding Y, Cadwell K. An enteric virus can replace the beneficial function of commensal bacteria. Nature. 2014;516:94U223. doi:10.1038/nature13960

17. Prescott JF, Parreira VR, Mehdizadeh Gohari I, et al. The pathogenesis of necrotic enteritis in chickens: what we know and what we need to know: a review. Avian Pathol. 2016;45:288-294. doi:10.1080/03079457.2016.1139688

18. Wang B, Hussain A, Zhou Y, et al. Saccharomyces boulardii attenuates inflammatory 510 response induced by Clostridium perfringens via TLR4/TLR15-511 MYD8 Pathway in HD11 Avian Macrophages. Poultry Sci. 2020;99:5356-5365. doi:10.1016/j. psj.2020.07.045

19. Broom LJ. The sub-inhibitory theory for antibiotic growth promoters. Poultry Sci. 2017;96:3104-3108. doi:10.3382/ps/pex114

20. Teillant A, Brower CH, Laxminarayan R. Economics of Antibiotic Growth Promoters in Livestock. Annu Rev Resour Econ. 2015;7:349-374. doi:10.1146/annurev-resource-100814-125015

21. Yang H, Paruch L. Antibiotic application and resistance in swine production in china: current situation and future perspectives. Front Vet Sci;2019. 6. doi:10.3389/fvets.2019.00136

22. Sethiya NK. Review on natural growth promoters available for improving gut health of poultry: an alternative to antibiotic growth promoters. Asian J Poult Sci. 2016;10:1-29.

23. Smith JM. A review of avian probiotics. J Avian Med Surg. 2014;28 (2):87-94. doi:10.1647/2012-031

24. Buntyn JO, Schmidt TB, Nisbet DJ, et al. The Role of Direct Fed Microbials in Conventional Livestock Production. Annu Rev Anim Biosci. 2016;4:335-355. doi:10.1146/annurev-animal-022114-111123

25. Cheng GY. Antibiotic alternatives: the substitution of antibiotics in animal husbandry? Front Microbiol. 2014;5.

26. Mehdi Y, Létourneau-Montminy M-P, Gaucher M-L, et al. Use of antibiotics in broiler production: global impacts and alternatives. Anim Nutr. 2018;4:170-178. doi:10.1016/j.aninu.2018.03.002

27. Chiang -S-S, Pan T-M. Beneficial effects of Lactobacillus paracasei subsp. paracasei NTU 101 and its fermented products. Appl Microbiol Biotechnol. 2012;93(3):903-916. doi:10.1007/s00253011-3753-x

28. Lee K, Lillehoj HS, Siragusa GR. Direct-fed microbials and their impact on the intestinal microflora and immune system of chickens. J Poultry Sci. 2010;1-26.

29. Yang Y, Iji P, Choct M. Dietary modulation of gut microflora in broiler chickens: a review of the role of six kinds of alternatives to in-feed antibiotics. World's Poultry Sci J. 2009;65(1):97-114. doi:10.1017/S0043933909000087

30. Chen CY, Chen SW, Wang HT. Effect of supplementation of yeast with bacteriocin and Lactobacillus culture on growth performance, cecal fermentation, microbiota composition, and blood characteristics in broiler chickens. Asian-Aust J Anim Sci. 2017;30:211-220. doi:10.5713/ajas.16.0203

31. Chen YS, Yanagida F, Shinohara T. Isolation and identification of lactic acid bacteria from soil using an enrichment procedure. Lett Appl Microbiol. 2005;40(3):195-200. doi:10.1111/j.1472765X.2005.01653.x

32. Heravi RM. Screening of lactobacilli bacteria isolated from gastrointestinal tract of broiler chickens for their use as probiotics. Afr J Microbiol Res. 2011;5:1858-1868.

33. Zakeri A, Kashefi P. The comparative effects of five growth promoters on broiler chickens humoral immunity and performance. J Anim Vet Adv. 2011;10:1097-1101. doi:10.3923/javaa.2011.1097.1101

34. Wang Y, Gu Q. Effect of probiotics on growth performance and digestive enzyme activity of arbor acres broilers. Res Vet Sci. 2010;89:163-167. doi:10.1016/j.rvsc.2010.03.009

35. Shim Y. Evaluation of multi-microbial probiotics produced by submerged liquid and solid substrate fermentation methods in broilers. Asian-Australas J Anim Sci. 2010;23:521-529. doi:10.5713/ ajas. 2010.90446 
36. Landy N, Kavyani A. Effect of using multi-strain probiotic on performance, immune responses, and cecal microflora composition in broiler chickens reared under heat stress condition. Iran J Appl Anim Sci. 2014;3:703-708.

37. Chichlowski M. Microarchitecture and spatial relationship between bacteria and ileal, cecal, and colonic epithelium in chicks fed a direct-fed microbial, PrimaLac, and Salinomycin. Poult Sci. 2007;86:1121-1132. doi:10.1093/ps/86.6.1121

38. Chichlowski M. Direct-fed microbial Primalac and Salinomycin modulate whole-body and intestinal oxygen consumption and intestinal mucosal cytokine production in the broiler chick. Poult Sci. 2007;86:1100-1106. doi:10.1093/ps/86.6.1100

39. Bajagai YS. Probiotics in Animal Nutrition: Production, Impact, and Regulation. Roma, Italia: FAO; 2016.

40. Lawrence T, Fowler V, Novakofski J. Growth promoters', performance enhancers, feed additives, and alternative approaches. 2012. Growth Farm Animals. 325-333. Ed. 3.

41. Lee A, Lee YJ, Yoo HJ, et al. Consumption of dairy yogurt containing Lactobacillus paracasei ssp. paracasei, Bifidobacterium animalis ssp. lactis and heat-treated Lactobacillus plantarum improves immune function including natural killer cell activity. Nutrients. 2017;9 (6):558. doi:10.3390/nu9060558

42. Orlando A. Antiproliferative and proapoptotic effects of viable or heat-killed Lactobacillus paracasei IMPC2. 1 and Lactobacillus rhamnosus GG in HGC-27 gastric and DLD-1 colon cell lines. Nutr Cancer. 2012;64(7):1103-1111. doi:10.1080/01635581.2012.717676

43. Dupont I, Roy D, Lapointe G. Comparison of exopolysaccharide production by strains of Lactobacillus rhamnosus and Lactobacillus paracasei grown in chemically defined medium and milk. $J$ Ind Microbiol Biotechnol. 2000;24(4):251-255. doi:10.1038/sj. jim. 2900810

44. Avlami A, Kordossis T, Vrizidis N, et al. Lactobacillus rhamnosus endocarditis complicating colonoscopy. $J$ Infect. 2001;42 (4):283-285. doi:10.1053/jinf.2001.0793

45. De Vrese M. Impact of oral administration of four Lactobacillus strains on Nugent score-systematic review and meta-analysis. Benef Microbes. 2019;10(5):483-496. doi:10.3920/BM2018.0129

46. Al-Khalaifah H. Benefits of probiotics and/or prebiotics for antibiotic-reduced poultry. Poult Sci. 2018;97(11):3807-3815. doi: $10.3382 / \mathrm{ps} /$ pey 160

47. Singh S. Effects of dietary supplementation of probiotics on broiler chicken. Animal Nutr Feed Technol. 2009;9(1):85-90.

48. Banday M, Risam K. Growth performance and carcass characteristics of broiler chicken fed with probiotics. Indian J Poultry Sci. 2001;36 (3):252-255.

49. Park I, Lee Y, Goo D, et al. The effects of dietary Bacillus subtilis supplementation, as an alternative to antibiotics, on growth performance, intestinal immunity, and epithelial barrier integrity in broiler chickens infected with Eimeria maxima. Poult Sci. 2020;99 (2):725-733. doi:10.1016/j.psj.2019.12.002

50. Ramarao S Growth, nutrient utilization and immune competence in broiler chicken fed probiotic, gut acidifier and antibacterial compounds. Indian J Poultry Sci. 2004;39(2):125-130.

51. Ramlucken U Advantages of Bacillus-based probiotics in poultry production. Livestock Sci. 2020;104215.

52. Ramlucken U, Ramchuran SO, Moonsamy G. et al. Production and stability of a multi-strain Bacillus-based probiotic product for commercial use in poultry. Biotechnol Rep;2020. e00575. doi:10.1016/j. btre.2020.e00575

53. Ramlucken U. Isolation, selection and evaluation of Bacillus spp. as potential multi-mode probiotics for poultry. J Gen Appl Microbiol. 2020;11-2019.

54. Khaksefidi A, Rahimi S. Effect of probiotic inclusion in the diet of broiler chickens on performance, feed efficiency and carcass quality. Asian-Australasian J Animal Sci. 2005;18(8):1153-1156. doi:10.5713/ajas.2005.1153
55. Samli H, Dezcan S, Koc F, et al. Effects of Enterococcus faecium supplementation and floor type on performance, morphology of erythrocytes and intestinal microbiota in broiler chickens. Br Poult Sci. 2010;51(4):564-568. doi:10.1080/00071668.2010.507241

56. Awad W, Ghareeb K, Abdel-Raheem S, et al. Effects of dietary inclusion of probiotic and synbiotic on growth performance, organ weights, and intestinal histomorphology of broiler chickens. Poult Sci. 2009;88(1):49-56. doi:10.3382/ps.2008-00244

57. Dong J-Y, Szeto IMY, Makinen K, et al. Effect of probiotic fermented milk on blood pressure: a meta-analysis of randomized controlled trials. $\quad B r \quad j \quad$ Nutr. 2013;110(7):1188-1194. doi:10.1017/ S0007114513001712

58. Mookiah S, Sieo CC, Ramasamy K, et al. Effects of dietary prebiotics, probiotics and synbiotics on performance, caecal bacterial populations and caecal fermentation concentrations of broiler chickens. J Sci Food Agric. 2014;94(2):341-348. doi:10.1002/ jsfa. 6365

59. Kabir S. The role of probiotics in the poultry industry. Int J Mol Sci. 2009;10(8):3531-3546. doi:10.3390/ijms10083531

60. Kabir S. Effect of probiotics on broiler meat quality. Afr J Biotechnol. 2009;8(15).

61. Salarmoini M, Fooladi M. Efficacy of Lactobacillus acidophilus as probiotic to improve broiler chicks performance. J Agric Sci Tech. 2011;13:165-172.

62. Kalavathy R, Abdullah N, Jalaludin S, et al. Effects of Lactobacillus cultures on growth performance, abdominal fat deposition, serum lipids and weight of organs of broiler chickens. Br Poult Sci. 2003;44(1):139-144. doi:10.1080/0007166031000085445

63. Smirnov A, Perez R, Amit-Romach E, et al. Mucin dynamics and microbial populations in chicken small intestine are changed by dietary probiotic and antibiotic growth promoter supplementation. J Nutr. 2005;135(2):187-192. doi:10.1093/jn/135.2.187

64. Pour JB, Kermanshahi H. Effects of cecal cultures and a commercial probiotic $\left(\right.$ PremaLac $^{\circledR}$ ) on performance and serum lipids of broiler chickens. J Animal Vet Adv. 2010;9(10):1506-1509. doi:10.3923/ javaa.2010.1506.1509

65. Shim Y, Ingale SL, Kim JS, et al. A multi-microbe probiotic formulation processed at low and high drying temperatures: effects on growth performance, nutrient retention and caecal microbiology of broilers. Br Poult Sci. 2012;53(4):482-490. doi:10.1080/ 00071668.2012 .690508

66. Zhang Z, Kim I. Effects of multistrain probiotics on growth performance, apparent ileal nutrient digestibility, blood characteristics, cecal microbial shedding, and excreta odor contents in broilers. Poult Sci. 2014;93(2):364-370. doi:10.3382/ps.201303314

67. Hossain M, Begum M, Kim I. Effect of Bacillus subtilis, Clostridium butyricum, and Lactobacillus acidophilus endospores on growth performance, nutrient digestibility, meat quality, relative organ weight, microbial shedding, and excreta noxious gas emission in broilers. Vet Med (Praha). 2015;60(2):77-86. doi:10.17221/7981-VETMED

68. Khan M, Raoult D, Richet H, et al. Growth-promoting effects of single-dose intragastrically administered probiotics in chickens. $\mathrm{Br}$ Poult Sci. 2007;48(6):732-735. doi:10.1080/00071660701716222

69. Dhande V. Effect of probiotic on performance of broilers. Poultry Guide. 1993;30:39-41.

70. Kabir SL, Rahman MM, Rahman. MB, et al. The Dynamics of Probiotics on Growth Performance and Immune Response in Broilers. Int $J$ Poult Sci. 2004;3(5):361-364. doi:10.3923/ ijps.2004.361.364

71. Bai S, Wu AM, Ding XM, et al. Effects of probiotic-supplemented diets on growth performance and intestinal immune characteristics of broiler chickens. Poult Sci. 2013;92(3):663-670. doi:10.3382/ ps.2012-02813

72. Anjum M. Effect of dietary supplementation of multi-strain probiotic on broiler growth performance. Pak Vet J. 2005;25(1):25-29. 
73. Poorghasemi M. Effect of Lactofeed probiotic and different sources of fat on performance, carcass characteristics and lipid parameters in broiler chickens. J Livestock Sci. 2017;8:143-149.

74. Poorghasemi M. Effect of probiotic and different sources of fat on performance, carcass characteristics, intestinal morphology and ghrelin gene expression on broiler chickens. Kafkas Üniversitesi Veteriner Fakültesi Dergisi. 2018;24(2).

75. Nafees M, Pagthinathan M. Effect of dietary supplementation of Lactobacilli and Streptococci cultures on the performance of broiler chickens. Dietary lactic acid cultures on broiler chicken growth. 2017;34-40.

76. Biernasiak J, Slizewska K. The effect of a new probiotic preparation on the performance and faecal microflora of broiler chickens. Vet Med (Praha). 2009;54(11):525-531. doi:10.17221/3075-VETMED

77. Samanta M. Effect of feeding probiotic and lactic acid on performance of broilers. West Bengal Univ Animal Fishery Sci. 1995;1-89.

78. Ashayerizadeh A, Dabiri N, Ashayeriza O, et al. Effect of Dietary Antibiotic, Probiotic and Prebiotic as Growth Promoters, on Growth Performance, Carcass Characteristics and Hematological Indices of Broiler Chickens. Pak J Biol Sci. 2009;12(1):52-57. doi:10.3923/ pjbs.2009.52.57

79. Yalçinkaya I. Mannan oligosaccharides (MOS) from Saccharomyces cerevisiae in broilers: effects on performance and blood biochemistry. Turkish J Vet Animal Sci. 2008;32(1):43-48.

80. Mountzouris K, Tsirtsikos P, Kalamara E, et al. Evaluation of the efficacy of a probiotic containing Lactobacillus, Bifidobacterium, Enterococcus, and Pediococcus strains in promoting broiler performance and modulating cecal microflora composition and metabolic activities. Poult Sci. 2007;86(2):309-317. doi:10.1093/ps/86.2.309

81. Patterson J, Burkholder K. Application of prebiotics and probiotics in poultry production. Poult Sci. 2003;82(4):627-631. doi:10.1093/ps/ 82.4 .627

82. Onderci M, Sahin N, Sahin K, et al. Efficacy of supplementation of $\alpha$-amylase-producing bacterial culture on the performance, nutrient use, and gut morphology of broiler chickens fed a corn-based diet. Poult Sci. 2006;85(3):505-510. doi:10.1093/ps/85.3.505
83. Gunal M, Yayli G, Kaya O, et al. The effects of antibiotic growth promoter, probiotic or organic acid supplementation on performance, intestinal microflora and tissue of broilers. Int J Poult Sci. 2006;5 (2):149-155. doi:10.3923/ijps.2006.149.155

84. Onderci M, Sahin N, Cikim G, et al. $\beta$-Glucanase-producing bacterial culture improves performance and nutrient utilization and alters gut morphology of broilers fed a barley-based diet. Animal Feed Sci Technol. 2008;146(1-2):87-97. doi:10.1016/j.anifeedsci.2007.11.005

85. Cao G, Zeng XF, Chen AG, et al. Effects of a probiotic, Enterococcus faecium, on growth performance, intestinal morphology, immune response, and cecal microflora in broiler chickens challenged with Escherichia coli K88. Poult Sci. 2013;92(11):2949-2955. doi:10.3382/ps.2013-03366

86. Mohan B, Kadirvel R, Natarajan A, et al. Effect of probiotic supplementation on growth, nitrogen utilisation and serum cholesterol in broilers. Br Poult Sci. 1996;37(2):395-401. doi:10.1080/ 00071669608417870

87. Ignatova M, Sredkova V, Marasheva V. Effect of dietary inclusion of probiotic on chickens performance and some blood indices. Biotechnol Animal Husb. 2009;25(5-6):1079-1085.

88. Sen S, Ingale SL, Kim YW, et al. Effect of supplementation of Bacillus subtilis LS 1-2 to broiler diets on growth performance, nutrient retention, caecal microbiology, and small intestinal morphology. Res Vet Sci. 2012;93(1):264-268. doi:10.1016/j. rvsc.2011.05.021

89. Rahimi S, Kathariou S, Grimes JL, et al. Effect of direct-fed microbials on performance and Clostridium perfringens colonization of turkey poults. Poult Sci. 2011;90(11):2656-2662. doi:10.3382/ ps.2011-01342

90. Timmerman H. Monostrain, multistrain and multispecies probiotics - a comparison of functionality and efficacy. Int J Food Microbiol. 2004;96(3):219-233. doi:10.1016/j.ijfoodmicro.2004.05.012

91. Bomba A, Nemcová R, Mudroňová D, et al. The possibilities of potentiating the efficacy of probiotics. Trends Food Sci Technol. 2002;13(4):121-126. doi:10.1016/S0924-2244(02)00129-2

\section{Publish your work in this journal}

Veterinary Medicine: Research and Reports is an international, peerreviewed, open access journal publishing original research, case reports, editorials, reviews and commentaries on all areas of veterinary medicine. The manuscript management system is completely online and includes a very quick and fair peer-review system. Visit $\mathrm{http}: / / \mathrm{www}$.dovepress.com/testimonials.php to read real quotes from published authors.

Submit your manuscript here: http://www.dovepress.com/veterinary-medicine-research-and-reports-journal 